\title{
Towards an AIDS vaccine The transmembrane envelope protein as target for broadly neutralizing antibodies
}

\author{
Joachim Denner
}

Robert Koch Institute; Berlin, Germany

Key words: AIDS, neutralizing antibodies, transmembrane envelope proteins, retroviruses

\begin{abstract}
Abbrevations: AIDS, acquired immunodeficiency syndrome; FeLV, feline leukemia virus; FPPR, fusion peptide proximal region; HAART, highly active antiretroviral therapy; HIV, human immunodeficiency virus; MPER, membrane proximal external region; PBMCs, peripheral blood mononuclear cells; PERV, porcine endogenous retroviruses; TM protein, transmembrane envelope protein
\end{abstract}

Although the development of an effective vaccine is the main goal in the fight against AIDS, all attempts by numerous laboratories to develop a vaccine have failed so far. In addition, it is still unclear whether cytotoxic T cells or neutralizing antibodies or both should be induced. The major advantage of neutralizing antibodies is their ability to prevent infection and subsequent integration of the provirus into the cellular genome where it may persist in a form invisible to the immune system. Broadly neutralizing antibodies have been found in HIV infected individuals, including antibodies directed against a highly conserved region in the membrane proximal external region (MPER) of the transmembrane envelope (TM) protein gp41 of HIV-1. We successfully induced neutralizing antibodies against different gammaretroviruses by immunization with their respective TM proteins. These antibodies recognized epitopes not only in the MPER but also in the fusion peptide proximal region of the TM protein. In the case of feline leukaemia virus (FeLV), these antibodies protected cats from antigenemia following challenge. To understand the mechanism of neutralization, the interactions between neutralizing antibodies and their corresponding epitopes in the TM protein of gammaretroviruses and HIV-1 were analyzed. These data may help to design antigens able to induce specific broadly neutralizing antibodies.

\section{Introduction}

In 2008, 33.4 million people lived with an infection by the human immunodeficiency virus (HIV), - which is the cause of the acquired immunodeficiency syndrome (AIDS), 2.7 million got newly infected, and an estimated 2 million people were

Correspondence to: Joachim Denner; Email: DennerJ@rki.de Submitted: 10/29/10; Accepted: 11/04/10

DOI: $10.4161 /$ hv.7.0.14555 killed by AIDS, among them 300,000 children. Although the therapy has improved significantly in recent years, AIDS still cannot be cured, and the combination therapy or HAART (highly active antiretroviral therapy) is associated with severe side effects. Therefore a prophylactic vaccination is the best means to prevent further distribution of the HIV pandemic. However, all attempts to design effective vaccines have failed so far.

Since HIV-1, like all retroviruses, integrates its genetic information into the genome of the infected cells where it may persist undetected from the immune system, induction of neutralizing antibodies preventing infection and integration seems to be the best vaccination strategy. Neutralizing antibodies usually interact with the surface and/or the TM proteins involved in the infection process and may thus prevent infection. Both proteins are exposed on the virus surface as trimeric envelope spikes (Fig. 1).

\section{Function of the TM Protein during Infection}

The structure of the envelope proteins and the mechanism of infection are very similar for all retroviruses (Fig. 1). The surface envelope protein, gp120 in the case of HIV-1 and gp70 in the case of gammaretroviruses, interacts with the receptor molecule(s) on the cell surface. The CD4 molecule and the chemokine receptors CXCR5 or CCR4 are the receptors for gp120 of HIV-1; different transporter molecules are the receptors for gp70 of gammaretroviruses. ${ }^{1,2}$ After interaction of the surface envelope proteins with the receptors, the glycine-rich fusion peptide at the $\mathrm{N}$-terminus of the TM protein intercalates into the cellular membrane and conformational changes in the TM protein, including an interaction of the C-helical and N-helical regions of the TM proteins, bring the membrane proximal external region (MPER) close to the fusion peptide proximal region (FPPR). This promotes fusion between viral and cellular membranes and internalization of the virus into the target cell. ${ }^{1,3}$ 


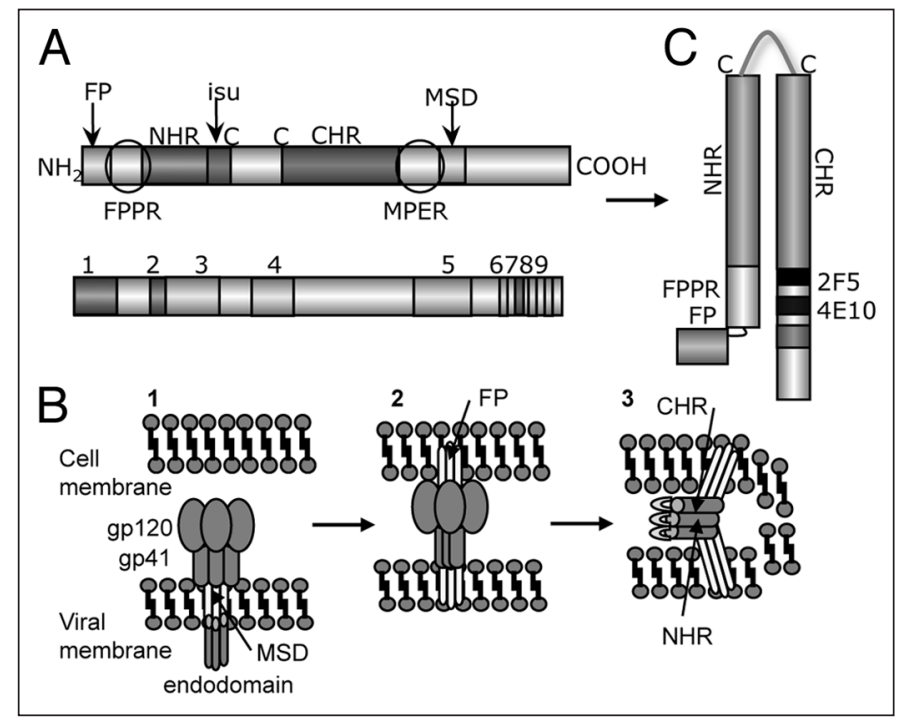

Figure 1. (A) Main functional domains of the retroviral TM protein (FP, fusion peptide; FPPR, fusion peptide proximal region; NHR, N-terminal helical region; isu, immunosuppressive domain; C-C, Cys-Cys-loop; CHR, C-terminal helical region; MPER, membrane proximal external region; MSD, membrane spanning domain). Below the membranotropic domains are indicated, the darker the shade of grey, the greater the effect ${ }^{45}$ (1) corresponds to the FP, (2 and 3) to a part of NHR, (4) to the Cys-Cys-loop, (5) to the MPER and MSD, (6 to 9) are located in the endodomain of gp41. (B) Schematic presentation of the conformational changes during infection. (1) localization of the viral knob consisting of the surface envelope protein gp120 and the TM protein gp41 anchored by the MSD in the viral membrane, (2) invasion of the fusion peptide into the cellular membrane, prehairpin intermediate and (3) hairpin or six-helix-bundle formation by the CHR and NHR. (C) Localization of the epitopes recognized by the broadly neutralizing antibodies $2 \mathrm{~F} 5$ and 4 E10 in the MPER of gp41 of HIV-1.

\section{Neutralizing Antibodies Specific for the TM Protein in AIDS Patients}

Low amounts of neutralizing antibodies were commonly found in HIV-infected individuals, most of them directed against the SU protein. ${ }^{4-9}$ Antibodies against the TM protein are mainly non-neutralizing and directed against the immunodominant Cys-Cys loop..$^{10,11}$ Usually patients develop antibodies against the immunodominant region (called cluster I), the C-terminal helical region (cluster II), the MPER (cluster IV), but not against the N-terminal region of gp41 including the fusion peptide, the FPPR or polar region and the $\mathrm{N}$-terminal helical region. ${ }^{12,13}$ The humoral immune response to gp 41 during HIV infection is strong with titers up to 625 -fold higher than anti-gp120 titers $^{14}$ and precedes the response against gp $120 .{ }^{15}$ In addition, broadly neutralizing antibodies such as $2 \mathrm{~F} 5$ and $4 \mathrm{E} 10$, directed at the MPER of gp 41 (Fig. 1) and neutralizing up to $95 \%$ of all HIV strains, were isolated from infected individuals. ${ }^{16-22}$ Passive infusion of mixtures of $2 \mathrm{~F} 5,4 \mathrm{E} 10$ and two neutralizing antibodies directed at gp120, 1b12 and 2G12, into rhesus monkeys protects against SHIV infection. If these antibodies could be induced in man, a preventive HIV-1 vaccine might be possible. ${ }^{23,24}$ Also, these antibodies reduced the virus load in humans after cessation of the antiretroviral therapy. ${ }^{25,26}$ In addition, when $2 \mathrm{~F} 5$ and 4E10 were characterized, uncommon properties were observed: (1) they are characterized by an uncommonly long hydrophobic CDR3 region; ${ }^{27,28}$ (2) 4E10, but not $2 \mathrm{~F} 5$, reacts with cardiolipin. ${ }^{29-31}$ Previously it was thought that 2F5/4E10-like antibodies are rare in HIV-1 infected individuals. Meanwhile, however, there is evidence that such antibodies are more common. ${ }^{12,32-34}$ Most importantly, broadly neutralizing antibodies reacting with the MPER may recognize epitopes different from those of $2 \mathrm{~F} 5$ and $4 \mathrm{E} 10 .{ }^{34}$

\section{Attempts to Induce Neutralizing Antibodies Specific for the TM Protein of HIV-1}

Several novel immunogen design strategies were developed in the past: (1) preserving the native structure of functional Env trimers or stabilization of the trimers by cross-linking; (2) unmasking of epitopes; (3) stabilization of intermediated epitopes; and (4) using structural analogs of conserved regions such as the MPER (reviewed in refs. 35 and 36). All attempts to generate broadly neutralizing antibodies such as 2F5 and 4E10 failed. ${ }^{37-42}$ Conformational constraints such as enhancement of the alphahelicity resulted in increased antigenicity, but no neutralizing response. ${ }^{39,40}$ Binding of $2 \mathrm{~F} 5$ and $4 \mathrm{E} 10$ to their epitopes requires surprisingly few crucial residues in their epitope domains (LEL DKW ANL, the epitope of 2F5 and NWF N(D)I SNW LW, the epitope of 4E10, amino acid changes to produce resistance to the corresponding antibody occurred only in the residues shown in bold), ${ }_{2}^{43}$ indicating that not the sequence, but the conformation of epitopes is of great importance. Different reasons, why it is difficult to induce 2F5/4E10-like antibodies were discussed: (1) they represent autoimmune antibodies; ${ }^{29-31}$ (2) other antibodies against gp41 may mask the epitopes in the MPER. ${ }^{44}$ The most likely explanation is that it is difficult to reconstruct the conformation of the epitope at a particular time during the conformational changes of gp 41 in the infection process. In addition, a strong interaction of different domains of the TM protein of HIV with lipids was observed (Fig. 1). ${ }^{45}$ When the interaction between the $\mathrm{mAb} 4 \mathrm{E} 10$ and its epitope in the lipid membrane was studied, it was shown that the MPER undergoes unexpected conformational changes upon binding of the antibody, ${ }^{46}$ showing the complexity and flexibility of the interaction between epitope and antibody.

Only a few publications reported immunization studies resulting in weakly neutralizing antibodies. For example, stable mimetics of the gp41 pre-hairpin intermediate were used to induce $\mathrm{D} 5$-like antibodies. ${ }^{38} \mathrm{D} 5$ is a monoclonal reacting with the NHR of the pre-hairpin. The concentration of the neutralizing antibodies was very low. When the MPER of gp 41 was presented in hepatitis B surface antigen (HBsAG) S1 protein that forms nanoparticles in the presence of lipids, no neutralizing antibodies were induced. However prime boost immunization with proteoliposomes containing HBsAG-MPER and the $\mathrm{HIV}$ envelope protein did raise neutralizing antibodies. ${ }^{47} \mathrm{~A}$ trimeric form of a chimeric protein composed of the triple stranded coiled-coil region from the influenza hemagglutinin subunit 2, HIV gp41 CHR and MPER also did not induce neutralizing antibodies. ${ }^{37}$ In contrast to these mostly unsuccessful attempts to 


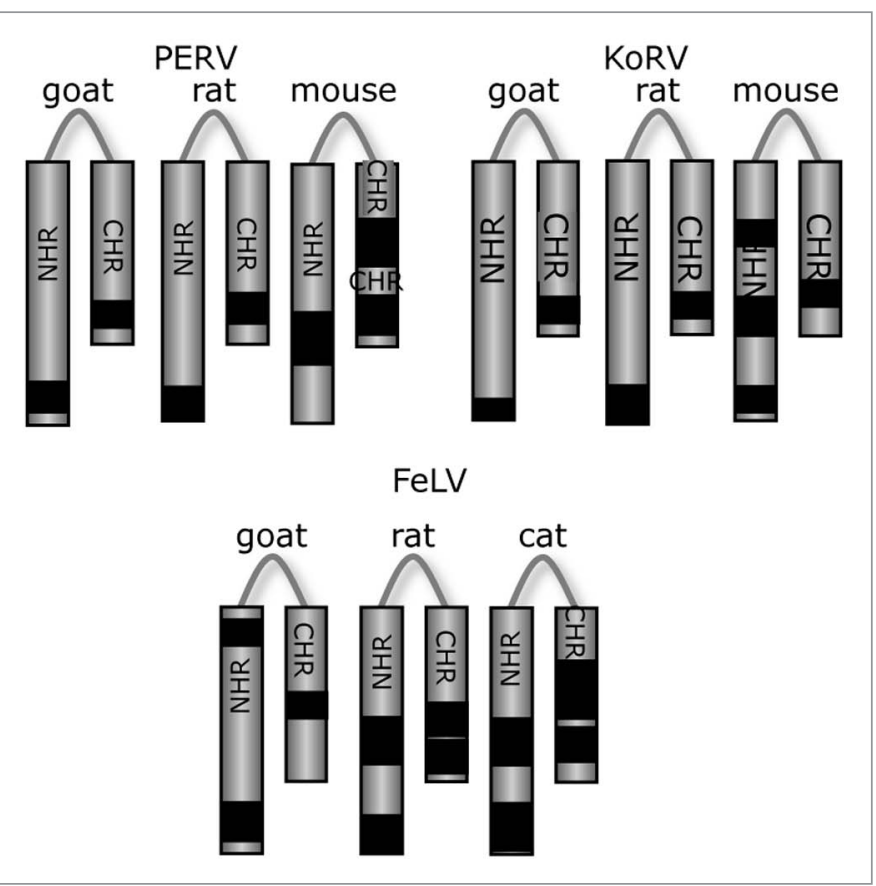

Figure 2. Localization of the epitopes (black) recognized by neutralizing antisera induced in different species (goat, rat, mouse, cat) after immunization with the TM proteins p15E of PERV, FeLV and KoRV. The fusion peptide and the membrane spanning domain are not shown.

induce broadly neutralizing antibodies recognizing the MPER of gp 41 of HIV, immunization studies with the TM proteins of different gammaretroviruses reproducibly resulted in neutralizing antibodies (see below).

\section{Successful Induction of Antibodies Neutralizing Gammaretroviruses by Immunization with their TM Protein}

Corresponding immunization studies were first performed with the TM protein of porcine endogenous retroviruses (PERVs), in connection with virus safety in xenotransplantation using pig cells or organs. Transplantation of pig cells or organs into human recipients is under development to help overcome the lack of human donor organs. Pigs, like all mammals, carry endogenous retroviruses in their genome. These porcine endogenous retroviruses (PERVs) were shown to be released from normal pig cells and to infect human cells, representing a special risk in xenotransplantation. The development of a PERV-specific vaccine may help to prevent transmission of the virus to xenotransplant recipients. To generate such a vaccine, goats, rats and mice were immunized with the TM protein p15E of PERV..$^{48}$ In all immunization studies neutralizing antibodies were obtained and, when the epitopes of the corresponding sera were analyzed, one epitope was found in the FPPR of p15E, designated E1, another in the MPER, designated E2 (Fig. 2). Surprisingly the localization of the epitope in the MPER was similar to the localization of the epitopes of 2F5 and 4E10 in the TM protein gp41 if HIV-1. Despite the evolutionary difference between
1 AAIGALFLGFLGAAGSTMGAASMTLTVOAROLLSDIVQQQ

2 AAIAALFLGELGAAGSTMGAASMTLTVQARQLLSDIVQQQ

3 AAIGALFLGFLGAAGSTMGAASMTLTVQARQLLSDIVQQQ

4 AAIGALFLGFLGAAGSTMGAASMTLTVQARQLLSDIVQQQ

5 AAIGALFLGFLGAAGSTMGAASMTLTVQARQLLSDIVQQQ

6 NEQELLELDKWASLWNWFNITNWLWY

Figure 3. Domains in the FPPR and MPER interacting with each other and with the monoclonal antibodies $2 \mathrm{~F} 5$ and $4 \mathrm{E} 10$. (1 and 5) represent the sequence Env512-552 in the FPPR, (6) is the sequence Env656-681 in the MPER. (1) a synthetic peptide corresponding to the underlined sequence, enhances the binding of $2 \mathrm{~F} 5$ to the peptide NEQ ELL ELD KWA SLW containing the epitope of $2 \mathrm{~F} 5$ (the epitope is underlined), ${ }^{54,55}$ (2) the underlined sequence was reported to be recognized by $4 \mathrm{E} 10$ with the boxed sequence as core epitope, ${ }^{59}$ (3) the underlined sequence enhances binding of $2 \mathrm{~F} 5$ to its epitope, ${ }^{60}$ (4) the underlined sequence was found to interact with the $\mathrm{FPPR}_{1}{ }^{56}(5)$ a peptide corresponding to the underlined sequence supports formation of a stable six-helix bundle when added to the NHR peptide number (6) and (6) sequence Env656-681, a peptide corresponding to the underlined sequence supports formation of a stable six-helix bundle when added to the peptide number (5), the epitopes of 2F5 and 4E10 are boxed..$^{57}$

the lentivirus HIV-1 and the gammaretrovirus PERV a limited sequence homology of the epitopes was observed. The epitope FEGWFN in p15E corresponds in localization and sequence to the epitope NWFN(D)IT in gp41 of HIV-1 recognized by the broadly neutralizing antibody 4E10 (identical amino acids in bold). Whereas immunizations of goats with p15E of PERV resulted in sera recognizing only two epitopes, ${ }^{48}$ immunization of rats and mice resulted in sera recognizing up to two epitopes in the FPPR and two additional in the MPER (designated E1a and E1b as well as E2a and E2b, unpublished data). The epitopes E2a and E2b in p15E of PERV correspond to the epitopes of 2F5 and 4E10 in gp41 of HIV-1. Preliminary data indicate that only the antibodies directed against the epitopes in the MPER/ E2 region are involved in neutralization; however the function of the E1 region is still unclear, and we cannot exclude the presence of additional antibodies which do not recognize linear peptides used for epitope mapping.

Since there is no animal model to analyze the neutralizing activity of sera against the TM protein p15E of PERV, similar immunization studies were performed with the TM protein p15E of FeLV. FeLV induces leukemias and immunodeficiencies in cats. Immunization studies in goats, rats and cats resulted in strongly neutralizing antibodies and the sera recognized epitopes localized in the FPPR and MPER ${ }^{49-52}$ (Fig. 2). The epitope FEGWFN is identical in FeLV and PERV and corresponds in localization and sequence to the epitope NWFN(D)IT in gp41 of HIV-1 recognized by the broadly neutralizing antibody 4E10 (identical epitopes in bold). Despite the fact that cats carry the sequence of the epitopes in $\mathrm{p} 15 \mathrm{E}$ in the form of endogenous feline retroviruses in their genome, cats also produce antibodies against these domains. ${ }^{51}$ When cats were immunized with $\mathrm{p} 15 \mathrm{E}$ of FeLV and challenged with infectious virus, protection from 
Table 1. Criteria for the characterization of neutralizing antibodies

Neutralizing in two different neutralization assays, e.g., based on measurement of provirus integration by real time PCR and TZM-bl cell based assay

Neutralizing activity is dose-dependent and can be diluted out

Neutralizing antibodies bind to the antigen used for immunization in Western blot assays, ELISA or immunoprecipitation

Epitope was identified

Neutralizing activity confirmed in an independent laboratory

antigenemia was observed in three out of six immunized cats $(50 \%)$, whereas all three non-immunized cats got infected and died from leukemia. ${ }^{50}$ These data indicate that immunization with the TM protein of a retrovirus induces protective immunity. In parallel, cats were immunized with the recombinant surface envelope protein gp70 of FeLV (which is the commercial vaccine Leucogen). Immunized with gp70, all cats were protected. Moreover, when cats were immunized with a combination of gp70 and p15E, higher titres of neutralizing antibodies were observed (unpublished data). The same results were obtained when rats were immunized simultaneously with gp70 and p15E of FeLV ${ }^{52}$ or PERV (unpublished data). In addition, when goats, rats and mice were immunized with p15E of the KoRV, neutralizing antibodies were induced ${ }^{53}$ and similar epitopes were observed as in the case of FeLV and PERV (unpublished data).

\section{Interaction between the MPER and FPPR}

When the epitopes of the monoclonal antibodies 2F5 and 4E10 were mapped, using the same method as used for the epitope mapping of goat, rat, cat and mice sera after immunization with the TM proteins of different gammaretroviruses such as PERV, FeLV and KoRV, only one epitope was recognized by each monoclonal antibody which was localized in the MPER. ${ }^{54}$ In order to analyze whether a domain in the FPPR may be involved in the mechanism of neutralization by $2 \mathrm{~F} 5$ and 4E10, overlapping peptides corresponding to the entire surface envelope protein gp120 and the TM protein gp41 of HIV-1 were used in order to study which of these peptides enhance the binding of 2F5 and $4 \mathrm{E} 10$ to a peptide containing their epitopes. One peptide was identified, enhancing the binding of 2F5 and 4E10 to their epitopes, located in the FPPR just opposite the MPER ${ }^{54,55}$ (Fig. 1). Although neither 2F5 nor 4E10 did bind to this FPPR-derived peptide, the presence of this peptide increased binding of the antibodies to their epitopes three to four times, indicating that interaction between the FPPR-derived and the MPER-derived peptides results in a conformation allowing better binding of $2 \mathrm{~F} 5$ or 4E10. A direct interaction between the FPPR-derived and the MPER-derived peptides was confirmed by surface plasmon resonance (SPR). ${ }^{54}$ This interaction suggests that, for the induction of neutralizing antibodies of the type 2F5/4E10, simultaneous use of both domains may be essential. ${ }^{55}$ Meanwhile, other publications also support the interaction of domains in the FPPR and the MPER during the conformational changes occurring during infection of HIV-1. ${ }^{56-58}$ (Fig. 3) It should be mentioned that, besides the interaction between $4 \mathrm{E} 10$ and 2F5 and their epitopes in the MPER, binding of both antibodies to regions in the FPPR have been reported, ${ }^{59,60}$ although not distinctly characterized. Interestingly, no interaction was found by SPR analysis between peptides corresponding to the E1 domain and the E2 domain in the MPER of p15E of PERV (unpublished data).

\section{False Positive Results in Neutralization Assays}

The problem of false positive results in neutralization assays is a still largely underestimated topic. Analyses of sera from animals immunized with TM proteins of different gammaretroviruses as well as with gp41-derived proteins or peptides often show false positive results. False positive results were also observed when preimmune sera were analyzed. Isolation of the immunoglobulins sometimes, but not always, eliminated the false positive effect. There are only speculations on how such false positive effects may be generated. For example, uncompleted coagulation processes, opsonizing antibodies, cross-reacting antibodies, cytokines induced by infections of the immunized animals with other microorganisms may cause inhibition of virus infection in neutralization assays. The influence of endotoxin on the results of neutralization assays was well studied. ${ }^{61}$ Endotoxin in the form of lipopolysaccharides may be released into sera by contaminating bacteria and can induce beta-chemokines in blood cell-based neutralization assays inhibiting HIV-1 infection as shown by. ${ }^{61}$ In addition, interferon gamma released from blood cells after interaction with endotoxin may give false positive results in TZM-bl cell-based neutralizing assays. Therefore, preparation, handling, transport, freeze-thawing and storage of preimmune and immune sera are of great importance when their neutralizing activity is investigated. As mentioned above, in some cases the use of purified immunoglobulins in neutralization assays together with epitope mapping confirming the binding to the TM protein may prove the specificity of the neutralizing antibodies. Neutralizing antibodies should be thoroughly characterized using strong criteria (Table 1).

\section{Influence of the Immunosuppressive Domain}

The immunosuppressive (isu) domain of the TM proteins of retroviruses is located in the $\mathrm{C}$-terminal part of the $\mathrm{N}$-terminal helical region of the protein (Fig. 1). The isu domain is highly conserved among all retroviruses, and peptides corresponding to this domain were shown to inhibit lymphocyte proliferation, to modulate cytokine release from normal peripheral blood mononuclear cells (PBMCs) and to modulate gene expression in normal PBMCs (reviewed in refs. 62-66). Mutations in the isu domain abrogated the immunosuppressive activity of the TM proteins, and immunization with TM proteins containing the mutated isu domain resulted in increased antibody responses (reviewed in refs. 67 and 68, and our own results), indicating that the isu domain should be inactivated in order to achieve an effective immunization against retroviral TM proteins. 


\section{Outlook}

Retroviral TM proteins undergo complex conformational changes during the infection process (Fig. 1). Intermediated structures, which are short-lived, may represent the required targets for neutralizing antibodies. To gain insight into antigenicity, immunogenicity and function of different domains of the TM proteins during infection, additional studies should be performed. Only if these complex conformations are characterized, corresponding antigens can be designed and neutralizing antibodies preventing retroviral infections including infections with HIV-1 can be induced.

\section{Acknowledgements}

I would like to thank Mrs. B. Brandi and Dr. V. Morozov for critical reading of the manuscript.

\section{References}

1. Chan DC, Kim PS. HIV entry and its inhibition. Cell 1998; 93:681-4.

2. Tailor CS, Lavillette D, Marin M, Kabat D. Cell surface receptors for gammaretroviruses. Curr Top Microbiol Immunol 2003; 281:29-106.

3. Melikyan GB. Common principles and intermediates of viral protein-mediated fusion: the HIV-1 paradigm. Retrovirology 2008; 10:5-111.

4. Walker LM, Phogat SK, Chan-Hui PY, Wagner D, Phung P, Goss JL, et al. Broad and potent neutralizing antibodies from an African donor reveal a new HIV-1 vaccine target. Science 2009; 326:285-9.

5. Li Y, Migueles SA, Welcher B, Svehla K, Phogat A, Louder MK, et al. Broad HIV-1 neutralization mediated by CD4-binding site antibodies. Nat Med 2007; 13:1032-4.

6. Simek MD, Rida W, Priddy FH, Pung P, Carrow E, Laufer DS, et al. Human immunodeficiency virus type 1 elite neutralizers: individuals with broad and potent neutralizing activity identified by using a high-throughput neutralization assay together with an analytical selection algorithm. J Virol 2009; 83:7337-48.

7. Kwong PD,Wyatt R, Robinson J, Sweet RW, Sodroski J, Hendrickson WA. Structure of an HIV gp120 envelope glycoprotein in complex with the CD4 receptor and a neutralizing human antibody. Nature 1998; 393:648-59.

8. Doria-Rose NA, Klein RM, Daniels MG, O'Dell S, Nason M, Lapedes A, et al. Breadth of human immunodeficiency virus-specific neutralizing activity in sera: clustering analysis and association with clinical variables. J Virol 2010; 84:1631-6.

9. Dey B, Pancera M, Svehla K, Shu Y, Xiang SH, Vainshtein J, et al. Characterization of human immunodeficiency virus type 1 monomeric and trimeric gp120 glycoproteins stabilized in the CD4-bound state: antigenicity, biophysics and immunogenicity. J Viro 2007; 81:5579-93.

10. Gnann JW Jr, Nelson JA, Oldstone MB. Fine mapping of an immunodominant domain in the transmembrane glycoprotein of human immunodeficiency virus. J Virol 1987; 61:2639-41.

11. Denner J, Norley S, Kurth R. The immunosuppressive peptide of HIV-1: functional domains and immune response in AIDS patients. AIDS 1994; 23:1063-72.

12. Pietzsch J, Scheid JF, Mouquet H, Seaman MS, Broder CC, Nussenzweig MC. Anti-gp41 antibodies cloned from HIV-infected patients with broadly neutralizing serologic activity. J Virol 2010; 84:5032-42.

13. Golding $\mathrm{H}$, Zaitseva M, de Rosny E, King LR, Manischewitz J, Sidorov I, et al. Dissection of human immunodeficiency virus type 1 entry with neutralizing antibodies to gp41 fusion intermediates. J Virol 2002; 76:6780-90.

14. Opalka D, Pessi A, Bianchi E, Ciliberto G, Schleif W, McElhaugh M, et al. Analysis of the HIV-1 gp41 specific immune response using a multiplexed antibody detection assay. J Immunol Methods 2004; 287:49-65.

15. McMichael AJ, Borrow P, Tomaras GD, Goonetilleke $\mathrm{N}$, Haynes BF. The immune response during acute HIV-1 infection: clues for vaccine development. Nat Rev Immunol 2010; 10:11-23.
16. Buchacher A, Predl R, Strutzenberger K, Steinfellner W, Trkola A, Purtscher M, et al. Generation of human monoclonal antibodies against HIV-1 proteins; electrofusion and Epstein-Barr virus transformation for peripheral blood lymphocyte immortalization. AIDS Res Hum Retroviruses 1994; 10:359-69.

17. Muster T, Steindl F, Purtscher M, Trkola A, Klima A Himmler G, et al. A conserved neutralizing epitope on gp41 of human immunodeficiency virus type 1. J Virol 1993; 67:6642-7.

18. Stiegler G, Kunert R, Purtscher M, Wolbank S, Voglauer R, Steindl F, et al. A potent cross-clade neutralizing human monoclonal antibody against a nove epitope on gp41 of human immunodeficiency virus type 1. AIDS Res Hum Retroviruses 2001; 17:1757-65.

19. Zwick MB, Labrijn AF, Wang M, Spenlehauer C Saphire EO, Binley JM, et al. Broadly neutralizing antibodies targeted to the membrane-proximal external region of human immunodeficiency virus type 1 glycoprotein gp41. J Virol 2001; 75:10892-905.

20. Mehandru S, Wrin T, Galovich J, Stiegler G, Vcelar B, Hurley A, et al. Neutralization profiles of newly transmitted human immunodeficiency virus type 1 by monoclonal antibodies 2G12, 2F5 and 4E10. J Virol 2004; 78:14039-42.

21. Binley JM, Wrin T, Korber B, Zwick MB, Wang M, Chappey C, et al. Comprehensive cross-clade neutralization analysis of a panel of anti-human immunodeficiency virus type 1 monoclonal antibodies. J Virol 2004; 78:13232-52.

22. Zwick MB, Labrijn AF, Wang M, Spenlehauer C Saphire EO, Binley JM, et al. Broadly neutralizing antibodies targeted to the membrane-proximal external region of human immunodeficiency virus type 1 glycoprotein gp41. J Virol 2001; 75:10892-905.

23. Ferrantelli F, Hofmann-Lehmann R, Rasmussen RA Wang T, Xu W, Li PL, et al. Post-exposure prophylaxis with human monoclonal antibodies prevented SHIV89.6P infection or disease in neonatal macaques. AIDS 2003; 17:301-9.

24. Ruprecht RM, Ferrantelli F, Kitabwalla M, Xu W, McClure HM. Antibody protection: passive immunization of neonates against oral AIDS virus challenge. Vaccine 2003; 21:3370-3.

25. Armbruster C, Stiegler GM, Vcelar BA, Jager W, Koller U, Jilch R, et al. Passive immunization with the anti-HIV-1 human monoclonal antibody (hMAb) $4 \mathrm{E} 10$ and the hMAb combination 4E10/2F5/2G12. J Antimicrob Chemother 2004; 54:915-20.

26. Trkola A, Kuster H, Rusert P, Joos B, Fischer $M$, Leemann C, et al. Delay of HIV-1 rebound after cessation of antiretroviral therapy through passive transfer of human neutralizing antibodies. Nat Med 2005; 11:615-22.

27. Zwick MB, Komori HK, Stanfield RL, Church S, Wang M, Parren PW, et al. The long third complementarity-determining region of the heavy chain is important in the activity of the broadly neutralizing anti-human immunodeficiency virus type 1 antibody 2F5. J Virol 2004; 78:3155-61.

28. Kunert R, Wolbank S, Stiegler G, Weik R, Katinger H. Characterization of molecular features, antigen-binding and in vitro properties of $\mathrm{IgG}$ and $\mathrm{IgM}$ variants of $4 \mathrm{E} 10$, an anti-HIV type 1 neutralizing monoclonal antibody. AIDS Res Hum Retroviruses 2004; 20:755-62.
29. Haynes BF, Fleming J, St. Clair EW, Katinger H, Stiegler G, Kunert R, et al. Cardiolipin polyspecific autoreactivity in two broadly neutralizing HIV-1 antibodies. Science 2005; 308:1906-8.

30. Verkoczy L, Diaz M, Holl TM, Ouyang YB, BoutonVerville H, Alam SM, et al. Autoreactivity in an HIV-1 broadly reactive neutralizing antibody variable region heavy chain induces immunologic tolerance. Proc Nat Acad Sci USA 2010; 107:181-6.

31. Matyas GR, Wieczorek L, Beck Z, OchsenbauerJambor C, Kappes JC, Michael NL, et al. Neutralizing antibodies induced by liposomal HIV-1 glycoprotein 41 peptide simultaneously bind to both the $2 \mathrm{~F} 5$ or $4 \mathrm{E} 10$ epitope and lipid epitopes. AIDS 2009; 23:2069-77.

32. Li Y, Svehla K, Louder MK, Wycuff D, Phogat S, Tang M, et al. Analysis of neutralization specificities in polyclonal sera derived from human immunodeficiency virus type 1-infected individuals. J Virol 2009; 83:1045-59.

33. Scheid JF, Mouquet H, Feldhahn N, Seaman MS, Velinzon K, Pietzsch J, et al. Broad diversity of neutralizing antibodies isolated from memory B cells in HIVinfected individuals. Nature 2009; 458:636-40

34. Gray ES, Madiga MC, Moore PL, Mlisana K, Abdool Karim SS, Binley JM, et al. Broad neutralization of human immunodeficiency virus type 1 mediated by plasma antibodies against the gp 41 membrane proximal external region. J Virol 2009; 83:11265-74.

35. Haynes BF, Montefiori DC. Aiming to induce broadly reactive neutralizing antibody responses with HIV-1 vaccine candidates. Expert Rev Vaccines 2006; 5:347-63.

36. McGaughey GB, Barbato G, Bianchi E, Freidinger RM, Garsky VM, Hurni WM, et al. Progress towards the development of a HIV-1 gp41-directed vaccine. Curr HIV Res 2004; 2:193-204.

37. Hinz A, Schoehn G, Quendler H, Hulsik DL, Stiegler $\mathrm{G}$, Katinger $\mathrm{H}$, et al. Characterization of a trimeric MPER containing HIV-1 gp41 antigen. Virology 2009; 390:221-7.

38. Bianchi E, Joyce JG, Miller MD, Finnefrock AC, Liang $\mathrm{X}$, Finotto M, et al. Vaccination with peptide mimetics of the gp 41 prehairpin fusion intermediate yields neutralizing antisera against HIV-1 isolates. Proc Natl Acad Sci USA 2010; 107:10655-60.

39. Ho J, Uger RA, Zwick MB, Luscher MA, Barber BH MacDonald KS. Conformational constraints imposed on a pan-neutralizing HIV-1 antibody epitope result in increased antigenicity but not neutralizing response. Vaccine 2005; 23:1559-73.

40. Joyce JG, Hurni WM, Bogusky MJ, Garsky VM, Liang $\mathrm{X}$, Citron MP, et al. Enhancement of alpha-helicity in the HIV-1 inhibitory peptide DP178 leads to an increased affinity for human monoclonal antibody $2 \mathrm{~F} 5$ but does not elicit neutralizing responses in vitro. Implications for vaccine design. J Biol Chem 2002; 277:45811-20

41. McGaughey GB, Citron M, Danzeisen RC, Freidinger RM, Garsky VM, Hurni WM, et al. HIV-1 vaccine development: constrained peptide immunogens show improved binding to the anti-HIV-1 gp41 MAb. Biochemistry 2003; 42:3214-23.

42. Zwick MB. The membrane-proximal external region of HIV-1 gp 41: a vaccine target worth exploring. AIDS 2005; 19:1725-37. 
43. Zwick MB, Jensen R, Church S, Wang M, Stiegler G, Kunert R, et al. Anti-human immunodeficiency virus type 1 (HIV-1) antibodies 2F5 and 4E10 require surprisingly few crucial residues in the membrane-proximal external region of glycoprotein gp41 to neutralize HIV-1. J Virol 2005; 79:1252-61.

44. Alam SM, Scearce RM, Parks RJ, Plonk K, Plonk SG, Sutherland LL, et al. Human immunodeficiency virus type 1 gp 41 antibodies that mask membrane proximal region epitopes: antibody binding kinetics, induction and potential for regulation in acute infection. J Virol 2008; 82:115-5.

45. Moreno MR, Giudici M, Villalaín J. The membranotropic regions of the endo and ecto domains of HIV gp41 envelope glycoprotein. Biochim Biophys Acta 2006; 1758:111-23

46. Sun ZY, Oh KJ, Kim M, Yu J, Brusic V, Song L, et al. HIV-1 broadly neutralizing antibody extracts its epitope from a kinked gp41 ectodomain region on the viral membrane. Immunity 2008; 28:52-63

47. Phogat S, Svehla K, Tang M, Spadaccini A, Muller J, Mascola J, et al. Analysis of the human immunodeficiency virus type $1 \mathrm{gp} 41$ membrane proximal external region arrayed on hepatitis $B$ surface antigen particles. Virology 2008; 373:72-84

48. Fiebig U, Stephan O, Kurth R, Denner J. Neutralizing antibodies against conserved domains of $\mathrm{p} 15 \mathrm{E}$ of porcine endogenous retroviruses: basis for a vaccine for xenotransplantation? Virology 2003; 307:406-13.

49. Langhammer $S$, Fiebig $U$, Kurth $R$, Denner J. Neutralising antibodies against the transmembrane protein of feline leukaemia virus (FeLV). Vaccine 2005; 23:3341-8.

50. Langhammer S, Hübner J, Jarrett O, Kurth R, Denner J. Immunization with the transmembrane protein of a retrovirus, feline leukemia virus: Absence of antigenemia following challenge. Antiviral Res, 2011; 89:119-123.

51. Langhammer $S$, Hübner J, Kurth R, Denner J. Antibodies neutralizing feline leukaemia virus (FeLV) in cats immunized with the transmembrane envelope protein p15E. Immunology 2006; 117;229-37.
52. Langhammer S, Fiebig U, Hübner J, Kurth R, Denne J. Increased neutralizing antibody response after simultaneous immunization with Leucogen and the feline leukemia virus transmembrane protein. Intervirology 2010; 54:78-86.

53. Fiebig U, Hartmann MG, Bannert $N$, Kurth $R$, Denner J. Transspecies transmission of the endogenous koala retrovirus. J Virol 2006; 80:5651-4.

54. Fiebig U, Eschricht M, Schmolke M, Kurth R, Denner J. Mode of interaction between the HIV-1 neutralizing monoclonal antibody 2F5 and its epitope. AIDS 2009; 23:887-95.

55. Fiebig U, Schmolke M, Karlas A, Kurth R, Denner J Induction of anti-viral neutralising antibodies. World Intellectual Property Organisation patent 2005; WO 2005/021574.

56. Bellamy-McIntyre AK, Lay CS, Baär S, Maerz AL, Talbo GH, Drummer HE, et al. Functional links between the fusion peptide-proximal polar segment and membrane-proximal region of human immunodeficiency virus gp 41 in distinct phases of membrane fusion. J Biol Chem 2007; 282:23104-16.

57. Noah E, Biron Z, Naider F, Arshava B, Anglister J. The membrane proximal external region of the HIV-1 envelope glycoprotein gp 41 contributes to the stabilization of the six-helix bundle formed with a matching $\mathrm{N}^{\prime}$ peptide. Biochemistry 2008; 47:6782-92.

58. Buzon V, Natrajan G, Schibli D, Campelo F, Kozloy MM, Weissenhorn W. Crystal structure of HIV-1 gp41 including both fusion peptide and membrane proximal external regions. PLoS Pathog 2010; 6:1000880.

59. Hager-Braun C, Katinger H, Tomer KB. The HIV neutralizing monoclonal antibody $4 \mathrm{E} 10$ recognizes $\mathrm{N}$-terminal sequences on the native antigen. J Immunol 2006; 176:7471-81.

60. Lorizate M, Gómara MJ, de la Torre BG, Andreu D, Nieva JL. Membrane-transferring sequences of the HIV-1 Gp41 ectodomain assemble into an immunogenic complex. J Mol Biol 2006; 360:45-55.
61. Geonnotti AR, Bilska M, Yuan X, Ochsenbauer C, Edmonds TG, Kappes JC, et al. Differential inhibition of human immunodeficiency virus type 1 in peripheral blood mononuclear cells and TZM-bl cells by endotoxin-mediated chemokine and gamma interferon production. AIDS Res Hum Retroviruses 2010; 26:279-91.

62. Denner J. Immunosuppression by oncogenic retroviridae In: Zschiesche W, ed. Immune modulation by infectious agents. Fischer Verlag, Jena 1987; 114-201.

63. Oostendorp RAJ, Meijer CJLM, Scheper RJ. Immunosuppression by retroviral-envelope-related proteins and their role in non-retroviral disease. Crit Rev Oncol Hematol 1993; 14:189-206.

64. Denner J. Immunosuppression by retroviruses: implications for xenotransplantation. Ann NY Acad Sci 1998; 862:75-86

65. Denner J. How does HIV induce AIDS? The virus protein hypothesis. J Hum Virol 2000; 3:81-2.

66. Denner J. Endogenous retroviruses. In: Kurth R, Bannert N, eds. Retroviruses: Molecular Biology, Genomics and Pathogenesis, Caister Academic Press, Hethersett, Norwich 2010; 35-69.

67. Schlecht-Louf G, Renard M, Mangeney M, Letzelter C, Richaud A, Ducos B, et al. Retroviral infection in vivo requires an immune escape virulence factor encrypted in the envelope protein of oncoretroviruses. Proc Natl Acad Sci USA 2010; 107:3782-7.

68. Mangeney M, Renard M, Schlecht-Louf G, Bouallaga I, Heidmann O, Letzelter C, et al. Placental syncytins: Genetic disjunction between the fusogenic and immunosuppressive activity of retroviral envelope proteins. Proc Natl Acad Sci USA 2007; 104:20534-9.

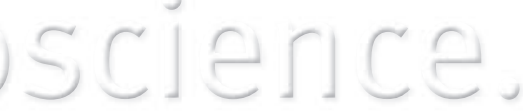

